\title{
QUALITY OF LIFE OF PATIENTS UNDERGOING HEMODIALYSIS
}

\author{
THENMOZHI P*
}

Research Scholar, Department of Nursing, Saveetha College of Nursing, Saveetha Institute of Medical and Technical Sciences, Chennai, Tamilnadu, India. Email: thenmozhi.sethu@gmail.com

Received: 29 November 2017, Revised and Accepted: 01 January 2017

ABSTRACT

Objective: The objective of the study was to assess the quality of life (QOL) of patients undergoing hemodialysis (HD). The QOL of HD patients was found to be considerably impaired when compared to that of healthy individuals of the general population. The careful assessment of QOL helps to guide and achieve medical management to optimize their health experience.

Methods: Cross-sectional research design was adopted with 130 samples who met the inclusion criteria to conduct the study in the dialysis unit, India. The instrument used for the study was to collect the data are demographic variable and kidney disease QOL - short form version 1.3 scale.

Results: The mean total score of QOL was $48.73 \pm 22.65$, the highest score was for dialysis staff encouragement scale (84.04 \pm 14.89 ) followed by social support scale $(80.38 \pm 20.38)$ and quality of social interaction $(71.52 \pm 18.74)$. However, role limitation caused by physical health problems, role limitation caused by emotional health, and burden of kidney disease scales yielded the lowest scores $(22.12 \pm 18.05,26.92 \pm 24.15$, and $38.03 \pm 12.81$, respectively)

Conclusion: The present study findings concluded that patients on HD were not having adequate QOL in all domains except patient satisfaction due to changes in the physiological, chemical changes occur in the kidney.

Key words: Quality of life, Hemodialysis, Chronic renal failure, End-stage renal disease, Health related quality of life.

(C) 2018 The Authors. Published by Innovare Academic Sciences Pvt Ltd. This is an open access article under the CC BY license (http://creativecommons. org/licenses/by/4. 0/) DOI: http://dx.doi.org/10.22159/ajpcr.2018.v11i4.24007

\section{INTRODUCTION}

Chronic diseases have become a major public health problem and the leading cause of morbidity and mortality [1]. Global status report on non-communicable diseases (2010) stated that $80 \%$ of chronic disease deaths worldwide occur in low- and middle-income countries [2]. Endstage renal disease (ESRD) is one among the chronic diseases which possess great threat globally and increased burden in the healthcare system and leads to increased morbidity and mortality and decreased the quality of life (QOL) [3]. According to the World Health Organization, Global Burden of Disease project, diseases of the kidney and urinary tract contribute to global burden with approximately 8,50,000 deaths every year and 11,50,10,107 disability-adjusted life years. Chronic kidney disease (CKD) is the $12^{\text {th }}$ leading cause of death and $17^{\text {th }}$ cause of disability. The global increase in CKD is being driven by the global increase in of diabetes mellitus, hypertension, obesity, and aging [4]. CKD is associated with increased incidences of cardiovascular mortality and loss of disability-adjusted QOL years [5]. CKD in India cannot be assessed accurately. The approximate prevalence of CKD is $800 \mathrm{pmp}$ and incidence of ESRD is 150-200 pmp [1].

ESRD is the final stage of CKD in which the kidneys no longer function well enough to meet the needs of daily life. During this stage, renal replacement therapy is required to stay live, and hemodialysis (HD) is considered as the most widely used therapy and playing an essential role in increasing patients' lifetime. The QOL of HD patients was found to be considerably impaired when compared to that of healthy individuals of the general population as well as of renal transplant patients [6].

QOL is an overall assessment of a person's well-being, which may include physical, emotional, and social dimensions, as well as stress level, sexual function, and self-perceived health status. End-stage renal failure is a chronic disease that exerts a great negative impact on patients' health-related QOL mainly due to the accompanied impairment or to the imposed limitations in almost all domains of their daily lives. Despite remarkable advances in the treatment of HD, the patients encounter certain physical, psychological, economic, and social problems which affect their QOL.

HD consist a complex procedure for patients that require frequent hospital or dialysis centers visits, mainly 3 times a week, thus implying substantial changes in the normal way of patients' living. 92\% of HD patients may endure a high symptom burden and may experience troubling symptoms such as fatigue, decreased appetite, trouble concentrating, swelling in their feet and hands, and muscle cramps, and, all of which cause daily distress and negatively affects their QOL [7]. HD is a time consuming, and costly treatment and it needs more restrictions for diet and fluid, and long run dialysis causes a loss of freedom, reliance on caregiver, disturbance of marriage, family, social live, and reduction or lack of income. All these factors impair QOL $[6,8]$.

Many studies found that CKD patients complain of depression, and other mental symptoms. On the other hand, little is known about patients and caregivers' health problems and their QOL [9]. HD-dependent patients with chronic renal failure, must cope with severe restrictions such as strict adherence to dialysis and medication regimens, dietary and fluid limitations, and minimal physical activities [10]. Problems with sleep are very common in ESRD (up to 40\%-80\%) and range from insomnia and sleep apnea to restless leg syndrome. Indeed, poor sleep is itself a predictor of mortality and QOL $[11,12]$. Continuous education and providing patient counseling could enhance adherence to therapies and thus could improve the QOL [13]. The careful assessment of healthrelated QOL (HRQOL) can help guide provision of medical management to optimize their health experience [14]. HRQOL is recognized as an essential health outcome for studies assessing the quality of healthcare, evaluating the impact of illness, and analyses of costeffectiveness $[12,15,16]$. In addition, it has been shown that HRQOL is clinically important for improving dialysis outcome in patients on HD $[17,18]$. With this background, the researcher interested to assess the QOL among ESRD patients who have undergone HD with respect to 
their all domains including physical health (PH), mental health, kidney disease problem, and patient satisfaction (PS).

\section{METHODS}

The research design adopted for the study was non-experimental, descriptive and cross-sectional study. The study was conducted in dialysis unit of the multispecialty hospital with 130 patients receiving HD regularly from April to June 2017 after obtaining Approval from Ethical Committee, and formal permission was obtained from the hospital authority. The samples were selected by convenient sampling technique who met the inclusion criteria. Patients with Stage V renal failure and on HD for more than 3 months with age group between 18 years and more than 71 years of both male and female, receiving HD 3 times per week or 2 times per week for $4 \mathrm{~h}$ per treatment, willing to sign an informed consent and participate in the study were included in the study. Patients who had dementia or other active mental disorders, neurological illness which may interfere the day to day activities of daily living, as well as mental health and hemodynamically unstable clients, were excluded from the study. The patients who consented in written form to participate were informed about the purpose of the study, rights to participate or withdraw from the study.

The instrument used for the study was to collect the data are demographic variable and Kidney Disease QOL - short form (KDQOL$\mathrm{SF}^{\mathrm{tm}}$ ) version 1.3 scale [19]. Demographic variables contained the information regarding age, sex, residence, marital status, educational status, occupational status, and income. It also includes the clinical variables such as family history of CKD, duration of ESRD since diagnosis, cause for kidney disease, duration of HD, and number of HD treatment per week.

KDQOL-SFTM is a multidimensional, reliable and validated questionnaire intended for dialysis patients. The survey instruments were translated into the local language (Tamil) as per the guidelines provided by the KDQOL working group. It has 43 domains targeted for ESRD (43 items) and has as its generic core the 36 domain of the short form Health Survey (SF-36). It consists of two parts, namely, diseasetargeted item and 36-item Health Survey.

Disease targeted item to focus on particular health related concerns of the patient with kidney disease and on dialysis: Symptoms/ problems - 12, effects of kidney disease - 8, burden of kidney disease - 4 , work status - 2, cognitive function - 3, quality of social interaction - 3 ,

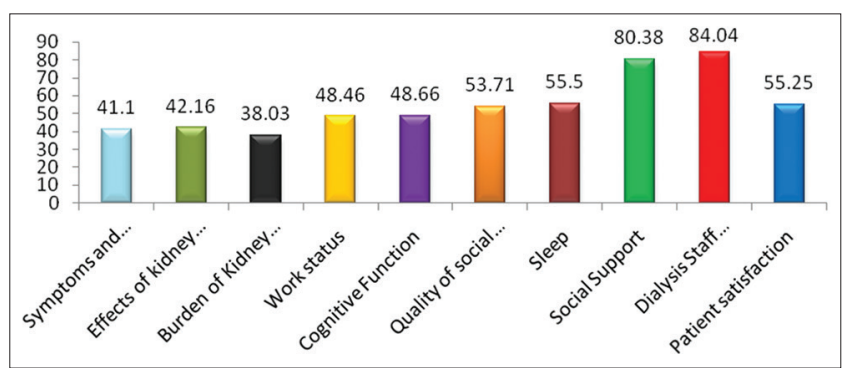

Fig. 1: Mean score of disease-targeted item

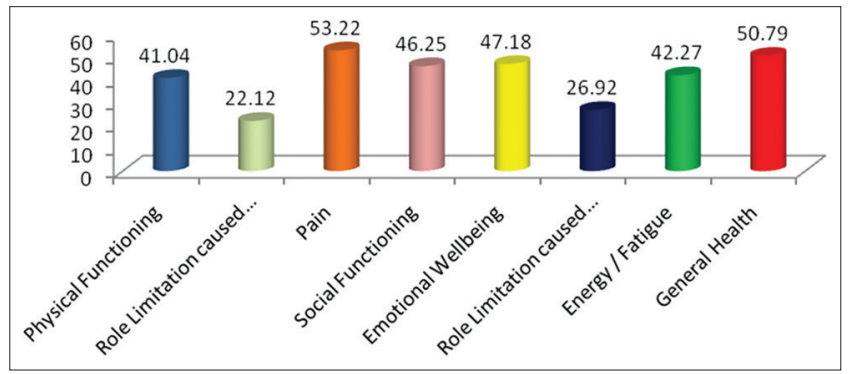

Fig. 2: Mean score of 36-item Health Survey sleep - 4, social support - 2, dialysis staff encouragement - 2, and PS - 1. 36-item Health Survey includes: Physical functioning - 10, role limitation caused by $\mathrm{PH}$ problem - 4, pain - 2, general health - 5, emotional wellbeing - 5 , role limitation caused by emotional problem - 3 , social function - 2 , and energy/fatigue -4 .

ESRD targeted domains are divided into four and each domain is further subdivided as follows:

1. PH: (a) Physical functioning, (b) work status, (c) role limitation due to physical function, (d) general health, (e) pain, (f) energy/fatigue, and $(\mathrm{g})$ social function

2. MH: (a) Emotional well-being, (b) quality of social interaction, (c) burden of kidney disease, (d) social support, and (e) role limitation due to emotional function.

3. Kidney disease problems: (a) Cognitive function, (b) symptoms/ problems, (c) effects of kidney disease, and (d) sleep.

4. PS: (a) PS and (b) staff encouragement

The participants were requested to answer by themselves after recall their experience of the past 4 weeks, and the researcher helped to fill the survey instruments. Each scale is scored as $0-100$, with a higher score indicating better QOL. They were assured about their confidentiality and anonymity throughout the study. The collected data prepared and scoring was done as per the KDQOL-SF ${ }^{\mathrm{tm}}$ Version 1.3 scale scoring manual using Microsoft Excel. QOL assessment was done by SPSS Software Statistical Package Version 1.8.

\section{RESULTS}

The study findings showed that of the 130 patients included in the study, $75(57.7 \%)$ were in the age group 50 years. The number of male $(85 \%)$ more than the female $(15 \%)$ and the majority of them $(61.5 \%)$ are residing in the rural area and rest of them are $22.3 \%$ and $16.2 \%$ residing in semi-urban and urban area, respectively. The marital status observed more than $84.6 \%$ were married. Regarding educational status, $53(40.8 \%)$ samples $(40.8 \%)$ were illiterate, followed by $60(46.2 \%)$ were completed the schooling up to primary school and only one subject was degree holder from our observation. More than $50 \%$ of the samples were housewife, and the majority of their monthly income was Rs.5000 and less than that. Data were presented in Table 1.

In the present study, clinical variables were also observed and represented in Table 2 which reveals that $26.9 \%$ of them have reported the family history of renal disease and diabetes mellitus $(24.6 \%)$ and hypertension was found to be the most frequent cause of ESRD. With regard to duration of ESRD since diagnosis $43.1 \%$ of them have $<1$ year followed with $45.4 \%$ have $1-3$ years and only one $(0.8 \%)$ of them has more than 5 years duration of ESRD. More than $51.6 \%$ of them were coming for HD regularly for past 1 year and $43.8 \%$ samples were undergoing HD for past 3 years and few samples $6(4.6 \%)$ were undergoing HD for more than 3 years and out of which $63.1 \%$ were coming thrice a week, and $36.9 \%$ were coming twice a week for HD.

The present study assessed the QOL in all subscales of disease-targeted item and 36-item Health Survey of KDQOL among study subjects. The mean total score was $48.73 \pm 22.65$; the highest score was for dialysis staff encouragement scale $(84.04 \pm 14.89)$ followed by social support scale $(80.38 \pm 20.38)$ and quality of social interaction $(71.52 \pm 18.74)$. However, role limitation caused by $\mathrm{PH}$ problems, role limitation caused by emotional health and burden of kidney disease scales yielded the lowest scores $(22.12 \pm 18.05,26.92 \pm 24.15$, and $38.03 \pm 12.81$, respectively). Sleep scale score was $55.50 \pm 8.56$ and pain scale score was $53.22 \pm 10.96$

The present study described the relationship of the clinical variables with the QOL using linear regression analysis, and then it was found that duration of HD ( $>2$ years) attained borderline significance (regression coefficient $=0.815 ; \mathrm{p}<0.049)$ in predicting the QOL $(\mathrm{p}<0.049)$ as shown in Table 4 . No other variable was found to be significant. 


\section{DISCUSSION}

QOL is a broad multidimensional concept that usually includes subjective evaluations of both positive and negative aspects of life [20] and it important to everyone. Long-term HD treatment often results in financial troubles, loss of freedom, dependence on healthcare personnel and caregivers, negative impacts on marital status, family, and social activities. Thus, QOL should be measured and monitored for a better understanding of patients' condition [21]. Several studies proved that HD patients suffer poor HRQOL, despite continuing advancements in the treatment [22-24]. With this regard, the present study assessed the QOL and background variables of patients undergoing HD. It was found that majority of the patients were male and in the age group of 51 years and above were not having adequate QOL in the domains of $\mathrm{PH}$, mental health, kidney disease problem and had better score in PS which reveals that they had good encouragement and interaction with the dialysis staff of both medical and nursing. Furthermore, it showed that had low score in role limitation caused by physical and emotional health due to signs and symptoms associated with kidney disease, which causes burden in their lives.

The findings are consistent with the study conducted by Abdelghany et.al., found that the mean total score was below 50 (out of 100 point) with mean $\mathrm{PH}$ composite $(\mathrm{PHC})=35.57 \pm 7.34$ and mean mental health composite $=36.76 \pm 10.22$ which revealed that all domains of HRQOL were reduced and very poor in HD patients. Anemia and unemployment adversely affected HRQOL scores [25]. The result of the study findings is parallel with the study conducted by Sathvik et.al. who reported that QOL of HD patients was significantly $(\mathrm{p}<0.05)$ lower in all the four WHOQOL-BREF domains [8]. Similarly a study conducted by Gerasimoula et.al., who stated that the total score of QOL was found to be higher in participants $<60$ years $(p=0,009)$, of higher educational

Table 1: Distribution of patients on HD according to demographic variables

\begin{tabular}{|c|c|c|}
\hline \multirow[t]{2}{*}{ S.no } & \multirow[t]{2}{*}{ Demographic variables } & \multirow{2}{*}{$\begin{array}{l}\text { Study group } \\
\text { n (\%) }\end{array}$} \\
\hline & & \\
\hline \multirow[t]{4}{*}{1} & Age in years & \\
\hline & $18-30$ & $13(10)$ \\
\hline & $31-50$ & $42(32.3)$ \\
\hline & More than 50 years & 75 (57.7) \\
\hline \multirow[t]{3}{*}{2} & Gender & \\
\hline & Male & $111(85.4)$ \\
\hline & Female & $19(14.6)$ \\
\hline \multirow[t]{4}{*}{3} & Residence & \\
\hline & Rural & $80(61.5)$ \\
\hline & Semi-urban & $29(22.3)$ \\
\hline & Urban & $21(16.2)$ \\
\hline \multirow[t]{5}{*}{4} & Marital status & \\
\hline & Married & $110(84.6)$ \\
\hline & Unmarried & $11(8.5)$ \\
\hline & Widow & $2(1.5)$ \\
\hline & Divorcee & $7(5.4)$ \\
\hline \multirow[t]{5}{*}{5} & Educational status & \\
\hline & Illiterate & $53(40.8)$ \\
\hline & Primary school & $60(46.2)$ \\
\hline & Higher secondary & $16(12.3)$ \\
\hline & Graduate and above & $1(0.8)$ \\
\hline \multirow[t]{5}{*}{6} & Occupational status & \\
\hline & Housewife & $66(50.8)$ \\
\hline & Daily Wages & $42(32.3)$ \\
\hline & Government job & - \\
\hline & Private job & $22(16.9)$ \\
\hline \multirow[t]{5}{*}{7} & Income in rupees & \\
\hline & Less than Rs. 5000/- & $115(88.5)$ \\
\hline & $5001-10,000 /-$ & $15(11.5)$ \\
\hline & $10,001-15,000 /-$ & - \\
\hline & More than $15,001 /-$ & - \\
\hline
\end{tabular}

HD: Hemodialysis level, being very informed about the health problem, complied with therapeutic recommendations and the proposed diet, having very good relations with the medical and nursing staff or other patients, not experiencing difficulties with social or family environment, had help at home and in those who did not conceal their health problem from the social environment and furthermore, it was found that the increasing duration of HD session entailed poorer QOL $(\mathrm{p}<0.001)$ which contrast with the present study findings [26].

Stojanovic and Stefanovic assessed the QOL and reported that HRQoL in patients on HD was found markedly impaired. Comorbid conditions have a negative and statistically significant correlation with parameters of HRQoL, and older age and poor income substantially reduce HRQoL in HD patients [27]. The present study demonstrated the correlation between the QOL and background variable, and it was with duration of HD. Duration of HD was found to be a significant factor for predicting the QOL. When the number of cycles per week increases the level of QOL is significantly decreased. On the other hand Anees et.al., who reported that unemployment is a positive predictor of QOL in social relation domain. Monthly income and place of residence is a positive predictor of QOL in environment domain [28]. Similarly in a study done by Bayoumi et.al., QoL is reduced in all the health domains of HD patients. Older age, male gender, unemployment, and duration of dialysis adversely affected the QoL scores [29].

In this study, Abdel-Kader et.al., who reported that the burden of symptoms, prevalence of depression, and low QOL are comparable in patients with ESRD and advanced CKD [30]. Mujais et.al. stated that baseline measures of HRQOL were reduced in CKD patients in proportion to the severity grade of CKD. Physical functioning score declined progressively with more advanced stages of CKD, and so did the score for role-physical [31]. Md Yusop et al. had conducted a study and reported that the kidney disease had a greater effect on $\mathrm{PH}$ than on mental health [32]. The present study assessed all the four domains of KDQOL in the study subjects. PH was significantly affected among all the four domains of the KDQOL, and an average score was found to be $25.45 \pm 11.85(\mathrm{p}<0.0015)$. The average value of $71.93 \pm 12.35 \%$ $(\mathrm{p}<0.029)$ subjects were having satisfaction with dialysis care, which is lower than the recommended value of $<65 \%$ [33]. Erythropoietin is one of the factors which extremely affect the QOL and study conducted

Table 2: Distribution of patients on HD according to clinical variables

\begin{tabular}{|c|c|c|}
\hline \multirow[t]{2}{*}{ S.no } & \multirow[t]{2}{*}{ Clinical variables } & \multirow{2}{*}{$\begin{array}{l}\text { Study group } \\
\text { n (\%) }\end{array}$} \\
\hline & & \\
\hline \multirow[t]{3}{*}{1} & Family history of ESRD & \\
\hline & Yes & 35 (26.9) \\
\hline & No & $95(73.1)$ \\
\hline \multirow[t]{5}{*}{2} & $\begin{array}{l}\text { Duration of ESRD since } \\
\text { diagnosis }\end{array}$ & \\
\hline & $<1$ year & $56(43.1)$ \\
\hline & $1-3$ years & $59(45.4)$ \\
\hline & $3-5$ years & $14(10.8)$ \\
\hline & More than 5 years & $1(0.8)$ \\
\hline \multirow[t]{6}{*}{3} & Cause for kidney disease & \\
\hline & Diabetes Mellitus & $32(24.6)$ \\
\hline & Hypertension & $44(33.8)$ \\
\hline & Polycystic kidney disease & $4(3.1)$ \\
\hline & Unknown etiology & $9(9)$ \\
\hline & Any other cause & $41(41)$ \\
\hline \multirow[t]{4}{*}{4} & Duration of HD & \\
\hline & 6 months - 1 year & $67(51.6)$ \\
\hline & $1-3$ years & $57(43.8)$ \\
\hline & More than 3 years & $6(4.6)$ \\
\hline \multirow[t]{3}{*}{5} & HD treatment per week & \\
\hline & Thrice in a week & $82(63.1)$ \\
\hline & Twice in a week & $48(36.9)$ \\
\hline
\end{tabular}

HD: Hemodialysis, ESRD: End-stage renal disease 
Table 3: Assessment of QOL among patients undergoing HD

\begin{tabular}{lll}
\hline Item & Mean \pm SD & Median \\
\hline Disease-targeted item & & \\
Symptoms and problems & $41.10 \pm 8.14$ & 41.66 \\
Effects of kidney disease on daily life & $42.16 \pm 9.75$ & 40.62 \\
Burden of kidney disease & $38.03 \pm 12.81$ & 37.50 \\
Work status & $48.46 \pm 23.24$ & 50.00 \\
Cognitive function & $48.66 \pm 11.69$ & 46.66 \\
Quality of social interaction & $53.71 \pm 9.59$ & 53.33 \\
Sleep & $55.50 \pm 8.56$ & 57.50 \\
Social support & $80.38 \pm 20.38$ & 83.33 \\
Dialysis staff encouragement & $84.04 \pm 14.89$ & 87.50 \\
PS & $55.25 \pm 42.22$ & 50.00 \\
36-item Health Survey & & \\
Physical functioning & $41.04 \pm 8.92$ & 40.00 \\
Role limitation caused by PH problems & $22.12 \pm 18.05$ & 25.00 \\
Pain & $53.22 \pm 10.96$ & 55.00 \\
Social functioning & $46.25 \pm 13.35$ & 50.00 \\
Emotional wellbeing & $47.18 \pm 15.33$ & 48.00 \\
Role limitation caused by emotional & $26.92 \pm 24.15$ & 33.33 \\
health & & \\
Energy/fatigue & $42.27 \pm 10.36$ & 40.00 \\
General health & $50.79 \pm 7.68$ & 50.00 \\
Total score & $48.73 \pm 15$ & 49.41 \\
\hline
\end{tabular}

SD: Standard deviation, QOL: Quality of life, PS: Patient satisfaction, PH: Physical health, HD: Hemodialysis

Table 4: Clinical factors related to QOL HD patients

\begin{tabular}{|c|c|}
\hline Regression coefficient $(95 \% \mathrm{CI})$ & $\mathbf{p}$ \\
\hline \multicolumn{2}{|l|}{ Family history } \\
\hline No reference category & $0.069(\mathrm{NS})$ \\
\hline \multicolumn{2}{|l|}{ Yes-1.24 (-2.56-0.08) } \\
\hline \multicolumn{2}{|l|}{ Duration of ESRD } \\
\hline \multicolumn{2}{|l|}{$<1$-year reference category } \\
\hline $1-3$ years $0.262(-1.58-1.05)$ & $0.696(\mathrm{NS})$ \\
\hline More than 3 years $0.065(-0.96-1.09)$ & $0.902(\mathrm{NS})$ \\
\hline \multicolumn{2}{|l|}{ Causes of ESRD } \\
\hline \multicolumn{2}{|l|}{ Diabetes mellitus reference category } \\
\hline Hypertension $0.566(-1.07-2.20)$ & $0.499(\mathrm{NS})$ \\
\hline Others $0.187(-0.59-0.96)$ & $0.638(\mathrm{NS})$ \\
\hline \multicolumn{2}{|l|}{ Duration of HD } \\
\hline$<1$ year reference category & $0.326(\mathrm{NS})$ \\
\hline $1-2$ years $-0.711(-2.12-0.70)$ & 0.049 \\
\hline \multicolumn{2}{|l|}{ More than 2 years $0.815(-1.61--0.02)$} \\
\hline \multicolumn{2}{|l|}{ HD cycle per week } \\
\hline \multicolumn{2}{|l|}{ Twice a week reference category } \\
\hline Thrice a week $0.807(-1.59--0.02)$ & $0.047(S)$ \\
\hline
\end{tabular}

QOL: Quality of life, HD: Hemodialysis, CI: Confidence interval, ESRD: End-stage renal disease, NS: Non-significant, S: Significant

by Sihombing et.al. had proved that erythropoietin can improve QOL of CKD patients with routine HD [34].

There are some limitations in the current study. The limitation of the present study was cross-sectional in design and not intensively analyses the factors associated with poor QOL, so there is a lack of cause and effect relationship. The study does not compare the QOL with their biochemical markers such blood urea, serum potassium, serum creatinine and hemoglobin, and dialysis adequacy such as Kt/V and urea reduction ratio which are also main influencing factors for the QOL. In future prospective interventional study can be conducted focused on interventions focused on providing resources for patients and their families including greater social support and increased selfefficacy.

\section{CONCLUSION}

The present study finding implies that patients on HD are not having adequate of life due to changes in the physiological, chemical changes occur in the kidney. The implementation of interdisciplinary and multidisciplinary approach consisting of dialysis technician, nurse, physician, nutritionist, physiotherapist, and clinical psychologist by designing structures exercise plan especially intradialytic exercise, dietetic strategies and yoga and meditation, counseling for psych emotional problem to focus on the physical and mental health problems to prevent further deterioration of the health status and to improve the QOL of HD patients and cope successfully with the full range of challenges encountered with kidney disease.

\section{ACKNOWLEDGMENT}

The author would like to thank all the participants for their active participation, cooperation and interest toward the study.

\section{REFERENCES}

1. Agarwal SK, Srivastava RK. Chronic kidney disease in India: Challenges and solutions. Nephron Clin Pract 2009;111:c197-203.

2. Available from: http://www.who.int/nmh/publications/ncd_report_ full_en.pdf.

3. Khan IA, Nasiruddin M, Haque SF, Khan RA. A randomized clinical trial to evaluate the efficacy and safety of $\alpha$-keto amino acids in stage 3 and 4 of chronic kidney disease. Asian J Pharm Clin Res 2014;7:21-4.

4. Schieppati A, Remuzzi G. Chronic renal diseases as a public health problem: Epidemiology, social, and economic implications. Kidney Int Suppl 2005;68:S7-10.

5. Raines N, González M, Wyatt C, Kurzrok M, Pool C, Lemma T, et al. Risk factors for reduced glomerular filtration rate in a Nicaraguan community affected by Mesoamerican nephropathy. MEDICC Rev 2014;16:16-22.

6. Sathvik BS, Parthasarathi G, Narahari MG, Gurudev KC. An assessment of the quality of life in hemodialysis patients using the WHOQOLBREF questionnaire. Indian J Nephrol 2008;18:141-9.

7. United States Renal Data System. United States Renal Data System 2012 Annual Data Report: Atlas of Chronic Kidney Disease and EndStage Renal Disease in the United States. Bethesda, MD: National Institutes of Health, National Institute of Diabetes and Digestive and Kidney Diseases; 2012. Available from: https://www.usrds.org/2012/ pdf/v1_00intro_12.pdf.

8. Mollaoglu M. Perceived social support anxiety and self-care among patients receiving haemodialysis. Dial Transplant 2006;35:144-55.

9. Shimoyama S, Hirakawa O, Yahiro K, Mizumachi T, Schreiner A, Kakuma $\mathrm{T}$, et al. Health-related quality of life and caregiver burden among peritoneal dialysis patients and their family caregivers in japan. Perit Dial Int 2003;23 Suppl 2:S200-5.

10. Devins GM, Mandin H, Hons RB, Burgess ED, Klassen J, Taub K, et al. Illness intrusiveness and quality of life in end-stage renal disease: Comparison and stability across treatment modalities. Health Psychol 1990;9:117-42.

11. Fukuhara S, Yamazaki S, Hayashino Y, Green J. Measuring healthrelated quality of life in patients with end-stage renal disease: Why and how. Nat Clin Pract Nephrol 2007;3:352-3.

12. Wan EY, Chen JY, Choi EP, Wong CK, Chan AK, Chan KH, et al. Patterns of health-related quality of life and associated factors in Chinese patients undergoing haemodialysis. Health Qual Life Outcomes 2015;13:108.

13. Baby B, Antony CL, Wilson S, Xavier T, Tamilselvan T. Evaluation of impact of pharmaceutical care on improving knowledge and medication adherence in CKD Patients. Int J Pharm Pharm Sci 2017;9:63-6.

14. Guyatt GH, Ferrans CE, Halyard MY, Revicki DA, Symonds TL, Varricchio $\mathrm{CG}$, et al. Clinical significance consensus meeting group: Exploration of the value of health-related quality-of-life information from clinical research and into clinical practice. Mayo Clin Proc 2007;82:1229-39.

15. Gusbeth-Tatomir P, Boisteanu D, Seica A, Buga C, Covic A. Sleep disorders: A systematic review of an emerging major clinical issue in renal patients. Int Urol Nephrol 2007;39:1217-26.

16. Elder SJ, Pisoni RL, Akizawa T, Fissell R, Andreucci VE, Fukuhara S, et al. Sleep quality predicts quality of life and mortality risk in haemodialysis patients: Results from the dialysis outcomes and practice patterns study (DOPPS). Nephrol Dial Transplant 2008;23:998-1004.

17. Hanly PJ, Pierratos A. Improvement of sleep apnea in patients with chronic renal failure who undergo nocturnal hemodialysis. N Engl $\mathrm{J}$ Med 2001;344:102-7.

18. Tang SC, Lam B, Ku PP, Leung WS, Chu CM, Ho YW, et al. Alleviation 
of sleep apnea in patients with chronic renal failure by nocturnal cyclerassisted peritoneal dialysis compared with conventional continuous ambulatory peritoneal dialysis. J Am Soc Nephrol 2006;17:2607-16.

19. Hays RD, Kallich JD, Mapes DL, Coons SJ, Carter WB. Development of the kidney disease quality of life (KDQOL) instrument. Qual Life Res 1994;3:329-38.

20. The world health organization quality of life assessment (WHOQOL): Development and general psychometric properties. Soc Sci Med 1998;46:1569-85.

21. Thaweethamcharoen T, Srimongkol W, Noparatayaporn P, Jariyayothin P, Sukthinthai N, Aiyasanon N, et al. Validity and reliability of KDQOL-36 in Thai kidney disease patient. Value Health Reg Issues 2013;2:98-102.

22. Mollaoglu M. Quality of Life in Patients Undergoing Hemodialysis. Hiromichi Suzuki. UK: Technology \& Medicine Open Access Book Publisher; 2013.

23. Joshi VD. Quality of life in end stage renal disease patients. World J Nephrol 2014;3:308-16.

24. Abraham S, Venu A, Ramachandran A, Chandran PM, Raman S. Assessment of quality of life in patients on hemodialysis and the impact of counseling. Saudi J Kidney Dis Transpl 2012;23:953-7.

25. Abdelghany MA, Elgohary EE, Nienaa YA. Assessment of healthrelated quality of life in patients receiving regular hemodialysis. J Nephrol Ther 2016;6:1-4

26. Gerasimoula K, Lefkothea L, Maria L, Victoria A, Paraskevi T, Maria P, et al. Quality of life in hemodialysis patients. Mater Sociomed
2015;27:305-9.

27. Stojanovic M, Stefanovic V. Assessment of health-related quality of life inpatients treated with hemodialysis in Serbia: Influence of comorbidity, age, and income. Artif Organs 2007;31:53-60.

28. Anees M, Malik MR, Abbasi T, Nasir Z, Hussain Y, Ibrahim M. Demographic factors affecting quality of life of hemodialysis patientsLahore, Pakistan. Pak J Med Sci 2014;30:1123-7.

29. Bayoumi M, Al Harbi A, AlSuwaida A, Al Ghonaim M, Al Wakeel J, Mishkiry A. Predictors of quality of life in hemodialysis patients. Saudi J Kidney Dis Transpl 2013;24:254-9.

30. Abdel-Kader K, Unruh ML, Weisbord SD. Symptom burden, depression, and quality of life in chronic and end-stage kidney disease. Clin J Am Soc Nephrol 2009;4:1057-64.

31. Mujais SK, Story K, Brouillette J, Takano T, Soroka S, Franek C, et al. Finkelstein. health-related quality of life in CKD Patients: Correlates and evolution over time. Clin J Am Soc Nephrol 2009;4:1293-301.

32. Md Yusop NB, Yoke Mun C, Shariff ZM, Beng Huat C. Factors associated with quality of life among hemodialysis patients in Malaysia. PLoS One 2013;8:e84152.

33. Murali R, Sathyanarayana D, Muthusethupathy MA. Assessment of quality of life in chronic kidney disease patients using the kidney disease quality of life-short form questionnaire in Indian population: A community based study. Asian J Pharm Clin Res 2015;8:271-4.

34. Sihombing J, Hakim L, Andayani TM, Irijanto F. Quality of life of chronic kidney disease patients with routine hemodialysis in general hospitals in sleman Yogyakarta. Int J Pharm Pharm Sci 2017;9:213-6. 